\title{
The Adverse Outcome Pathway for Oxidative Stress-Mediated EGFR Activation Leading to Decreased Lung Function
}

\author{
Karsta Luettich,' Marja Talikka,, Frazer J. Lowe,2 Linsey E. Haswell, \\ Jennifer Park, Marianna D. Gaca, and Julia Hoeng ${ }^{1}$
}

\begin{abstract}
The Adverse Outcome Pathway (AOP) framework provides a means to outline a knowledge-driven sequence of events from exposure to adverse outcome. As a concept, AOPs have been readily accepted by the toxicology community as a means to organize available mechanistic information linking exposures to toxic effects in a standardized way encompassing all organizational levels of a given biological system. However, there is also an inherent benefit in applying AOPs to health outcomes that are not necessarily linked to standard toxicological end points, for example, in the context of predicting disease risk or in drug development. In this study, we propose an AOP for decreased lung function that originates in oxidative stress-mediated epidermal growth factor receptor activation in the airway epithelium. This article provides an overview of the supporting evidence for key events (KEs) on the molecular, cellular, tissue/organ, and organism level and how they relate to each other through key event relationships (KERs). The essentiality of the identified KEs, as well as the biological plausibility of the KERs, is also assessed. Moreover, the envisioned application of the proposed AOP is discussed, highlighting the utility of the AOP framework for developing preclinical tests that could prove useful in public health risk assessment for long-term e-cigarette use.
\end{abstract}

Keywords: adverse outcome pathway, EGFR activation, mucus hypersecretion, decreased lung function

\section{Introduction}

$\mathbf{T}$ 'HE LUNGS' MUCOUS BARRIER is a natural defense against the harmful effects of inhaled xenobiotics, including respiratory toxicants and pathogens. ${ }^{1}$ Under physiological conditions, foreign particles are trapped in mucus and eliminated from the airways through mucociliary clearance. ${ }^{2}$ However, excessive mucus production can lead to impaired mucociliary clearance and airway obstruction and, eventually, result in decreased lung function. ${ }^{3}$ Excessive mucus production, or mucus hypersecretion, is a characteristic feature of chronic diseases such as chronic obstructive pulmonary disease (COPD), cystic fibrosis, and asthma, all of which pose a significant public health burden. Of note, exposure to cigarette smoke, occupational respiratory hazards, and air pollutants are clearly linked to the development of COPD, which is predicted to become the third leading cause of death worldwide by $2030{ }^{4,5}$ While regulation and public health measures seek to minimize exposures and thereby the incidence of the disease, airflow obstruction can be seen in $\sim 25 \%$ of adults aged 40 and over globally. ${ }^{6}$

Adverse outcome pathways (AOPs) provide a tractable modular framework for integrating existing mechanistic knowledge that connects chemicals or other stressors to a defined molecular initiating event (MIE) on the cellular level, subsequent downstream key events (KEs) at ever-increasing levels of biological hierarchy, and finally to a populationlevel adverse outcome (AO) of regulatory relevance. ${ }^{7}$ As

\footnotetext{
${ }^{1}$ Philip Morris International R\&D, Philip Morris Products S.A. (Part of Philip Morris International Group of Companies), Neuchâtel, Switzerland.

${ }^{2}$ British American Tobacco (Investments) Ltd., Southampton, United Kingdom.

${ }^{3}$ Selventa, Cambridge, Massachusetts.

(C) Karsta Luettich et al., 2017; Published by Mary Ann Liebert, Inc. This Open Access article is distributed under the terms of the Creative Commons License (http://creativecommons.org/licenses/by/4.0), which permits unrestricted use, distribution, and reproduction in any medium, provided the original work is properly cited.
} 
such, structured assembly of the available mechanistic information into an AOP is expected to prove useful for predicting public health outcomes based on tests that can be carried out rapidly and cost-effectively and that do not necessarily involve animal experimentation. For example, understanding how chronic exposure to inhaled toxicants leads to mucus hypersecretion is relevant to risk assessment of airborne pollutant and cigarette smoke exposure and elucidating how these exposures contribute to the development and progression of the disease. In addition, understanding the molecular underpinnings of these processes can aid in informing on early KEs, before onset of disease, and hence, public health risk-reduction strategies.

The following article proposes an AOP for decreased lung function that arises from oxidative stress-mediated epidermal growth factor receptor (EGFR) activation in the airway epithelium and provides an overview and evaluation of the existing mechanistic evidence as outlined in the Organization for Economic Cooperation and Development (OECD) handbook $^{8}$ in support of such an AOP. While the AO in this study is not a typical toxicological end point, it is hoped that the proposed AOP will find its future application not only in human risk assessment but also in human health research, as initially introduced by Langley et al. as "repurposing" of the AOP concept. ${ }^{9}$

\section{Summary of KEs and Mechanisms}

A schematic of the AOP is presented in Figure 1; the evidence collated to date is available on the AOP-Wiki (https:// aopwiki.org/aops/148, accessed December 12, 2016). Mucus hypersecretion in the airways is a key characteristic of many lung diseases, including asthma, cystic fibrosis, and chronic bronchitis. ${ }^{10}$ Mucus hypersecretion is characterized by an increase in the number of goblet cells, mucin synthesis, and mucus secretion, which can result in airway obstruction, decreased peak expiratory flow, and respiratory muscle weakness. ${ }^{10,11}$ EGFR-mediated signaling has been identified as the key pathway that leads to airway mucus hypersecretion ${ }^{12}$ and redox signaling as the major initiator of receptor activation. ${ }^{13}$ Therefore, we believe that the MIE of this AOP is oxidative stress leading to activation (phosphorylation) of $E G F R$ (KE1) on the surface of lung epithelial cells.

The EGFR family comprises four members: EGFR (also termed ErbB1/HER1), ErbB2/Neu/HER2, ErbB3/HER3, and ErbB4/HER4, all of which are transmembrane glycoproteins with an extracellular ligand-binding site and an intracellular tyrosine kinase domain. EGFR signaling is central to airway epithelial maintenance and mucin production, ${ }^{14}$ and EGFR expression has been demonstrated in lung epithelial cells (although weakly) under physiological, as well as pathological, conditions in vitro and in vivo. ${ }^{15-18}$ Of note, lung epithelial EGFR phosphorylation was reported to increase under conditions of oxidative stress, including exposure to hydrogen peroxide $\left(\mathrm{H}_{2} \mathrm{O}_{2}\right),{ }^{19}$ naphthalene, ${ }^{20}$ cigarette smoke, ${ }^{21,22}$ and in the presence of neutrophils or neutrophil elastase. ${ }^{23-26}$ EGFR activation by oxidative stress may have a number of root causes: Reactive oxygen species (ROS) were shown to increase production of epidermal growth factor, the prime EGFR ligand, by lung epithelial cells. ${ }^{27}$ Similarly, expression and secretion of transforming growth factor-alpha and amphiregulin (AREG), also EGFR ligands, were elevated in

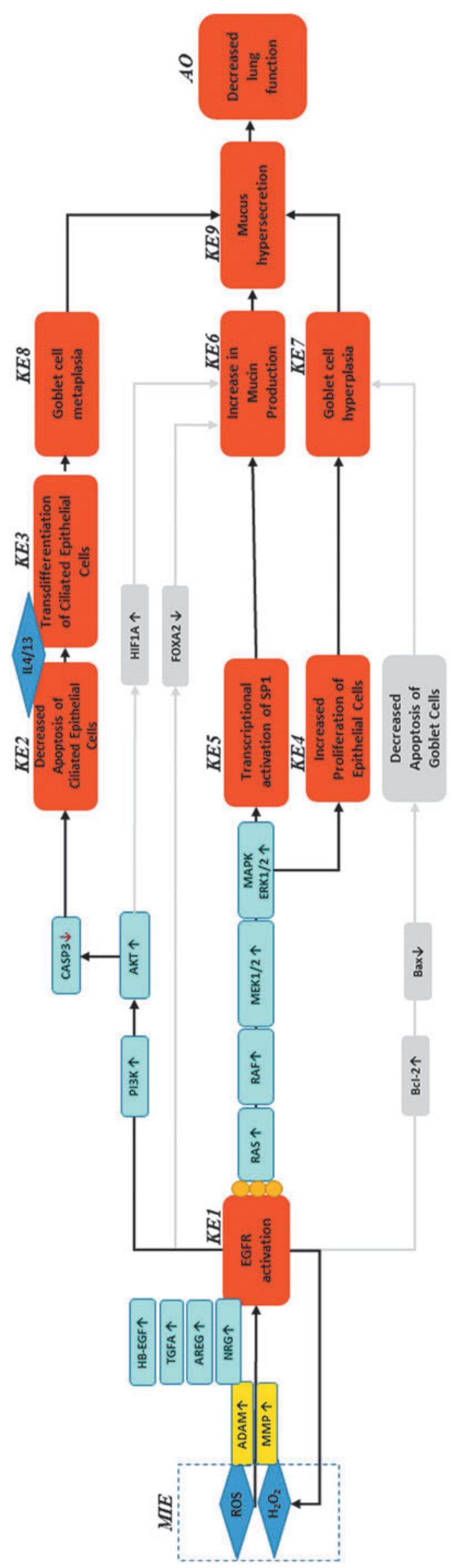


human bronchial epithelial cells in response to fine particulate matter $\left(\mathrm{PM}_{2.5}\right)$, diesel particulate matter, and cigarette smoke exposure. $^{28-30}$ Mechanistically, this process is dependent on ROS-mediated activation of metalloproteinases or members of the A disintegrin and metalloproteinase (ADAM) family of proteins, which cleave membrane-bound EGFR ligand precursors, making them locally available to bind to and transactivate EGFR in an autocrine manner. ${ }^{31-34}$ Importantly, ligand binding itself has been identified as a source of ROS, and specifically of $\mathrm{H}_{2} \mathrm{O}_{2}$, which function as second messengers potentially perpetuating the ensuing EGFR activation through chemical modification of the receptor. ${ }^{35,36}$ In addition, the presence of ROS may also contribute to EGFR activation by chemically modifying the receptor, thereby altering its structure and enhancing its kinase activity. ${ }^{35,37}$ While it is tempting to speculate that the increase in $\mathrm{H}_{2} \mathrm{O}_{2}$ would perpetuate EGFR activation through the continuous proteolytic shedding of proligands in an autocrine loop, multiple lines of evidence suggest that oxidative modification, specifically EGFR sulfenylation, contributes to enhanced tyrosine phosphorylation of the receptor and downstream signaling. ${ }^{13,35,38-40}$

Downstream of EGFR activation, phosphoinositide 3kinase $(\mathrm{PI} 3 \mathrm{~K}) /$ protein kinase $\mathrm{B}$ (AKT) signaling elicits an antiapoptotic response in ciliated cells, favoring their surviv$\mathrm{al}^{41}$ (KE2: Decreased Apoptosis of Ciliated Epithelial Cells). Subsequent stimulation by pro-inflammatory stimuli such as the Th2 cytokines interleukin (IL)- 4 and IL- 13 then promotes transdifferentiation of ciliated cells into goblet cells, thereby increasing the number of goblet cells ("second hit hypothesis") ${ }^{42}$ (KE3: Transdifferentiation of ciliated epithelial cells). Alternatively, classical downstream activation of the mitogen-activated protein kinase (MAPK)/extracellular signal-regulated kinase (ERK) pathway, also known as Raf/ Ras/MAPK/ERK pathway, increases airway epithelial cell proliferation $^{30,43,44}$ (KE4: Increased Proliferation of Epithelial Cells) and facilitates epithelial wound repair. ${ }^{12,20,45}$ While there is evidence that increased goblet cell proliferation may be the underlying cause of goblet cell hyperplasia (KE7: Goblet cell hyperplasia $(\mathrm{GCH})),{ }^{46}$ the key players mediating an increase in airway goblet cell numbers following EGFR activation are still largely unexplored. Basal epithelial cells which exhibit stem cell-like properties have been postulated to function as a source of goblet cells in injured airways, utilizing cell fate pathways that favor secretory cells over other cell populations. ${ }^{47}$ However, both in vitro studies and studies in mouse models of asthma, COPD, and viral infection indicate that transdifferentiation of ciliated or club cells into goblet cells, which is referred to as goblet cell metaplasia (KE8: Goblet cell metaplasia $(G C M))$, more likely contributes to the expansion of this cell population in the airways. $^{41,48-53}$ Furthermore, such increases in the number of goblet cells are suppressed when EGFR activity is inhibited. ${ }^{41}$

Once established, GCH and/or GCM are thought to be maintained by goblet cell overexpression of Bcl-2, an antiapoptotic protein, which may arise as a consequence of oxidative stress-mediated EGFR activation. ${ }^{54-57}$ Importantly, the increase in goblet cell numbers may directly contribute to increased mucin production (KE6: Increase in Mucin Production). Activation of EGFR by oxidative stress was shown to correlate with increased mucin mRNA and protein expression, involving classical EGFR signal transduction through the MAPK cascade to activate the Sp-1 (KE5: Sp-1 Activa- tion) or, at least in mice, hypoxia-inducible factor-1 alpha $(\mathrm{HIF}-1 \alpha)$ transcription factors that govern MUC5AC gene expression. ${ }^{58-64}$ In addition, activation of EGFR can also downregulate FOXA2, a known transcriptional repressor of mucin genes, although the underlying mechanism is currently unknown. ${ }^{65,66}$ Alternatively, mucin production could be stimulated by other, concomitant oxidative stressinduced, but EGFR-independent, processes known to contribute to GCH/GCM and increased expression of mucins. For example, Gensch et al. reported $M U C 5 A C$ upregulation in vitro and in vivo following cigarette smoke exposure and identified Src, ERK, c-Jun N-terminal kinase (JNK), and activator protein 1 (AP-1) activation as critical steps in mediating ROS effects in human airway tissues in vitro. ${ }^{67}$ Zhou et al. reported increased mucin expression in response to autophagy caused by cigarette smoke exposure in vitro and in vivo. ${ }^{68}$

Increased mucin production and mucus hypersecretion following acute exposure are thought to contribute to innate airway defenses and are most likely limited by anti-inflammatory mechanisms aimed at resolving the exposure-related stress. ${ }^{2,69}$ However, under chronic exposure conditions, airway remodeling will persist, leading to airway narrowing, and the elevated number of goblet cells results in higher basal mucus levels (KE9: Mucus Hypersecretion). ${ }^{70}$ Eventually, increased mucin production and mucus hypersecretion may lead to airway obstruction and a progressive decline in lung function over time (AO: Decreased Lung Function). ${ }^{11,71,72}$

\section{Biological Plausibility}

EGFR activation by oxidative stress in humans, mice, and rats is well documented, and EGFR and its ligands are orthologous in these species. EGFR activation by ligand binding and ligand-independent mechanisms is supported by studies with EGFR inhibitors such as AG1478 and BIBX 1522, efficiently abrogating downstream signaling and, hence, cell proliferation and survival. ${ }^{41,56,73}$ However, evidence for a specific EGFR-mediated effect in airway goblet or ciliated cells is limited and partially correlative, so biological plausibility for EGFR activation increasing proliferation of goblet cells and decreasing apoptosis of ciliated cells is only moderate. Another gap in current knowledge pertains to how inhibition of ciliated cell apoptosis leads to transdifferentiation that eventually contributes to an increase in goblet cell numbers. The available evidence is indirect or correlative. ${ }^{41,46,49,50,74,75}$ It also is not in agreement with other studies, which show that ciliated cells do not give rise to goblet cells during airway remodeling in rodents and humans, and with studies that provide evidence for increased goblet cell proliferation. ${ }^{4,56,76-78}$ Therefore, we consider biological plausibility for this KER $(\mathrm{KE} 2 \rightarrow \mathrm{KE} 3)$ to be moderate.

Transcriptional regulation of $M U C 5 A C$ expression and MUC5AC protein expression in the airways has been directly linked to EGFR-mediated activation of $\mathrm{Sp}-1 .{ }^{58,60,62,64}$ Although limited, the evidence appears to be highly reproducible across several studies in human airway epithelial cells, thereby supporting moderate biological plausibility of KERs KE1 $\rightarrow$ KE5: EGFR activation indirectly leading to Sp-1 activation and KE5 $\rightarrow \mathrm{KE6}: S p-1$ activation directly leading to increased mucin production. 
Studies in airway epithelial cells and in rats have demonstrated that GCH/GCM and increased mucin production following infection with Mycoplasma pneumonia and exposure to $\mathrm{PM}_{2.5}$, acrolein, or cigarette smoke can be greatly diminished by (pre-)treatment with EGFR inhibitors, ${ }^{34,79-83}$ supporting biological plausibility for this KER. However, owing to the fact that there is only correlational evidence linking increased goblet cell numbers to increased mucin production that coincides with strong EGFR expression in human airways ${ }^{84,85}$ plausibility for the KER KE7 $\rightarrow$ KE9 is moderate.

Chronic mucus hypersecretion is a main feature of chronic lung diseases, and the presence of GCH or GCM in COPD, asthma, and CF has been inferred as cause for sustained mucus production. ${ }^{2,86}$ Clinical studies have shown that MUC5AC expression in bronchial epithelium is inversely correlated with FEV1 (\% predicted) and with the FEV1/FVC ratio, ${ }^{87,88}$ two important diagnostic measures of lung function. Moreover, chronic mucus hypersecretion was reported to contribute to decreased lung function in a number of clinical studies. ${ }^{72,89,90}$ As a cause-effect relationship between GCH/ GCM, increased mucin production, mucus hypersecretion, and airway obstruction cannot be conclusively proven; these findings support moderate biological plausibility.

\section{Essentiality of KEs}

EGFR signaling is considered critical for mucus hypersecretion and $\mathrm{GCH} / \mathrm{GCM},{ }^{42}$ and numerous studies indicate that inhibition of EGFR decreases mucin production or goblet cell numbers. ${ }^{25,41,57,61,73,78,79}$ EGFR blockade also was reported to prevent an increase in goblet cell numbers and cause activation of caspase- 3 and loss of ciliated cells, indicating that EGFR is essential for decreased ciliated cell apoptosis. ${ }^{41}$ However, there is also evidence supporting decreased apoptosis in airway goblet cells in vitro, in a mouse model of asthma, and in rats following intratracheal lipopolysaccharide instillation, as a result of EGFR activation. ${ }^{56,73,91}$ Whether the latter only occurs once GCH/GCM is established, as indicated by Harris et al., ${ }^{54}$ or whether additional events are required to maintain $\mathrm{GCH} / \mathrm{GCM}$, is currently unclear.

Sp-1 binding sites are required for active MUC5AC gene expression, ${ }^{60}$ and $\mathrm{Sp}$-1-mediated mucin expression can be blocked by the Sp-1 inhibitor mithramycin A. ${ }^{61,92}$ However, since the MUC5AC promoter has multiple transcription factor binding sites, it is likely that alternative pathways contribute to increased mucin production, such as activation of HIF- $1 \alpha$ or decreased FOXA2 expression. ${ }^{65,93,94}$

Mucus hypersecretion is a physiological response to inhalation exposures such as pollutants or infectious agents. As such, it is typically of short duration and does not pose a major problem to normal lung function. However, in the presence of GCH, increased mucus production may decrease airflow. Since this may be accompanied by impaired mucociliary clearance and ineffective cough, ${ }^{69}$ and owing to the lack of direct evidence, it is currently unclear whether chronic mucus hypersecretion alone is sufficient to affect a decrease in lung function.

Considering the gaps in the current knowledge, in particular, when transitioning to the organizational level of the organism, we propose that three major independent mechanisms leading to mucus hypersecretion (KE9) exist: (1)
$\mathrm{MIE} \rightarrow \mathrm{KE} 1 \rightarrow \mathrm{KE} 2 \rightarrow \mathrm{KE} 3 \rightarrow \mathrm{KE} 8$, (2) $\mathrm{MIE} \rightarrow \mathrm{KE} 5 \rightarrow \mathrm{KE} 6$, and (3) MIE $\rightarrow$ KE4 $\rightarrow$ KE7. Whether all three mechanisms are necessary to cause mucus hypersecretion is difficult to evaluate. At least some of the evidence suggests that they may be executed in parallel as a result of EGFR activation by oxidative stress.

\section{Empirical Evidence}

Table 1 presents an overview of supporting empirical evidence for the KERs. Selection criteria applied to this evidence were based, as far as possible, on the OECD guidance and handbook for the development of AOPs ${ }^{8,95}$ and considered fitness for purpose, direct relationship to $\mathrm{KE}$, support for causality, and general acceptance by the scientific community. In brief, proof of EGFR activation (KE1) can be derived from western blots, for example, of untreated and treated cell or tissue lysates, using specific antibodies targeting the phosphorylated EGFR epitopes. Densitometry evaluation of the colorimetrically stained, chemiluminescent, or radioactive bands on the blot then permit a (semi-) quantitative measure of activation. Moreover, the addition of EGFR inhibitors or neutralizing antibodies is well suited to demonstrate causality.

Numerous proliferation and apoptosis assays exist. Traditionally, cell proliferation is determined by monitoring cell viability, and various means and methods exist to accomplish this. ${ }^{96,97}$ Similarly, cell death assays range from simple cellular stains for use with platforms such as flow cytometry for detection of specific markers, for example, caspase, to more sophisticated multiplex assays. ${ }^{98,99}$ In any case, inclusion of appropriate controls allows for quantitation of surviving or proliferating cell populations, as well as the extent and mode of cell death. That said, the evidence necessary to support cell death in a specific subpopulation of the airway epithelium would require identifying the cell type of interest first. This could be achieved by either staining the cell with a population-specific marker in situ or by enriching the population of interest before monitoring cell proliferation and death. To the best of our knowledge, to date only the double immunohistochemical/immunofluorescent staining of airway epithelial samples has been used to demonstrate increased proliferation of goblet cells (KE4) and decreased apoptosis of goblet or ciliated cells (KE2). ${ }^{41,77,79}$ Similarly, transdifferentiation (KE3) in the airway epithelium is difficult to quantify. A trained pathologist may assign a score that reflects the extent of airway remodeling in animal and human lung tissues, but no standard exists, and the results are at best semiquantitative and study-specific. Some investigators view the appearance of cells bearing morphological characteristics of both ciliated and goblet cells, and colocalization of ciliated and goblet cell markers in situ, as sufficient evidence for transdifferentiation. ${ }^{100,101}$ However, there is currently no quantitative evaluation of these data; in future studies, this could potentially be conducted using image analysis software.

Transcription factor activity can be evaluated by multiple means, including reporter gene assays, electrophoretic mobility shift assay, chromosomal immunoprecipitation, and array-based assays. Some of these assays are cumbersome and technically challenging, possess low sensitivity, and may even pose a financial burden to the investigator. ${ }^{102}$ 

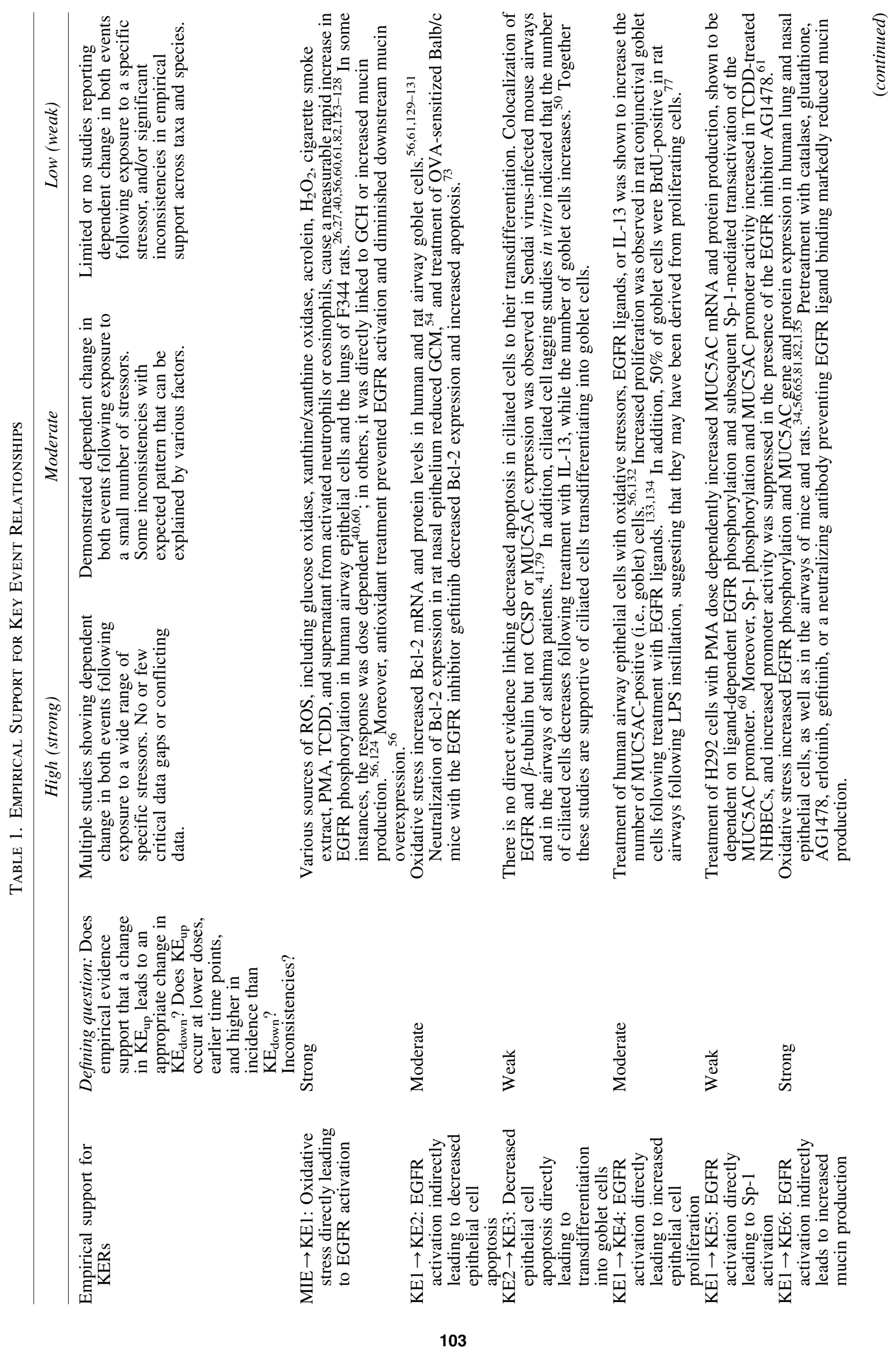


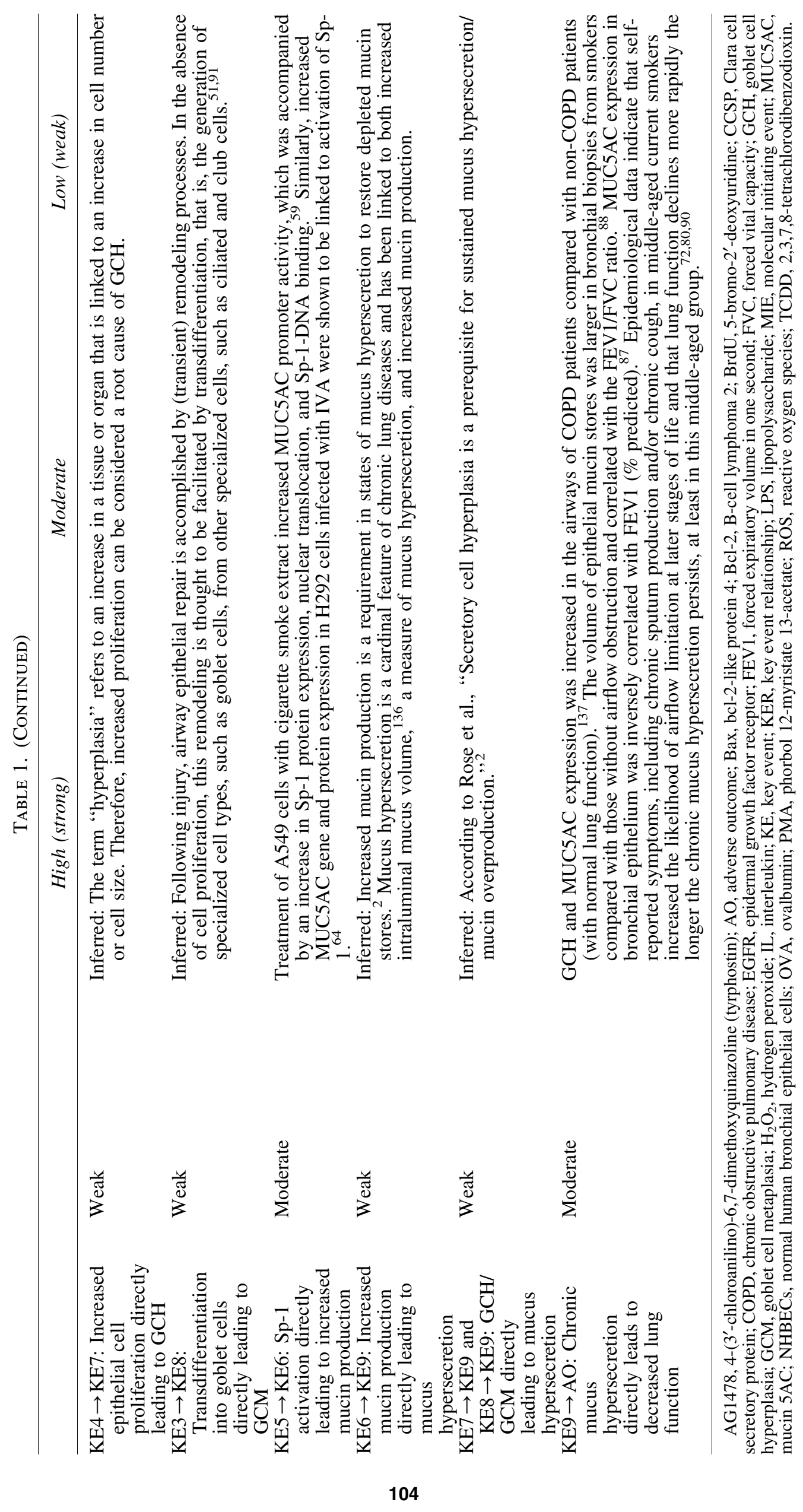


These may be among the reasons for the limited number of studies examining how EGFR activation impacts the transcription factor Sp-1 (KE5) directly and indirectly. ${ }^{60,62,64}$

In in vitro studies, a relative increase in MUC5AC gene and/or protein expression compared with control conditions is generally accepted as a surrogate measure of mucus hypersecretion (KE6). While this is true for some animal studies, mucus hypersecretion has also been concluded from increased Alcian blue/periodic acid-Schiff staining and the presence of goblet cells throughout the airways. Clinically, coughing and sputum production for $>3$ months in at least 2 consecutive years is defined as (chronic) mucus hypersecretion. ${ }^{103}$ As such, diagnosis depends on the extent of medical examination, including questioning the patient and subject recall. Current clinical practice, however, does not include a quantitative measure of mucus hypersecretion, making this event an inferred one. This is quite different from lung function assessment, for which extensive and widely accepted clinical guidelines exist; abnormal lung function (AO) as a diagnostic criterion for COPD is well defined. ${ }^{104,105}$

In summary, while the quantitation of some KEs included in the proposed AOP meets the criteria outlined in the OECD handbook, evaluating others is more problematic. There is good quantitative understanding of how oxidative stress affects EGFR signaling and influences mucus production, epithelial cell proliferation, apoptosis, and transdifferentiation, individually assayed. In addition, in the majority of these studies, the summary evidence indicates dose-response relationships, time-response relationships, and causality for oxidative stress-induced EGFR activation leading to increased cell proliferation, lending strong support for the KERs $\mathrm{MIE} \rightarrow \mathrm{KE} 1$ and $\mathrm{MIE} \rightarrow \mathrm{KE6}$. However, quantitative knowledge is lacking with respect to the identity of airway epithelial cells undergoing proliferation and apoptosis, processes purportedly forming a basis for subsequent transdifferentiation $(\mathrm{KE} 2 \rightarrow \mathrm{KE} 3, \mathrm{KE} 3 \rightarrow \mathrm{KE} 8, \mathrm{KE} 4 \rightarrow \mathrm{KE} 8)$, which makes empirical support for these KERs weak. Furthermore, while cause-effect relationships can be derived from studies investigating $\mathrm{Sp}-1$ activation, dose-response relationships are difficult to derive. Moreover, data in support of the KERs for increased mucin production (KE5 $\rightarrow$ KE6) and mucus hypersecretion at the organism level (KE6 $\rightarrow$ KE9, $\mathrm{KE} 7 \rightarrow \mathrm{KE} 9, \mathrm{KE} 8 \rightarrow \mathrm{KE} 9)$ are mainly derived from surrogate measures, and while those may not adequately reflect quantitative mucus production, they are accepted in the clinical community as an indicator of chronic bronchitis. Taken together, we judge the quantitative evidence for the KEs and KERs on the tissue and organism level to be weak.

\section{Domain of Applicability}

\section{Taxonomic applicability}

The evidence presented in this study in support of the proposed AOP for mucus hypersecretion and decreased lung function is derived from both human and rodent biological systems. In vitro and in vivo studies in these systems have been performed to clarify the mechanisms of EGFR activation and mucus hypersecretion by studying the increase in goblet cells and subsequent increase in mucin transcript and protein expression, as well as mucus production. ${ }^{2,70}$ In summary, these evidences suggest that the majority of KEs are preserved across small rodents and humans. There are also several clin- ical studies on mucus hypersecretion and how it affects lung function in humans with chronic bronchitis, asthma, and other chronic lung diseases. However, the link between mucus hypersecretion and airflow obstruction is much less supported by studies in laboratory animals where the human disease phenotype cannot be modeled in its entirety, and traditional lung function measurements are difficult. ${ }^{106,107}$

\section{Life stage applicability}

EGFR activation leading to mucus hypersecretion is predominantly studied in adults, although it was also reported in pediatric asthma and bronchitis. ${ }^{108,109}$ In general, the exposures resulting in oxidative stress to subsequently induce EGFR activation apply to adults who are more likely to be exposed to these stressors. Moreover, until a considerable time of exposure or since exposure has elapsed, that is, an advanced life stage has been reached, decreased lung function may go unnoticed unless accompanied by other symptoms such as cough and, hence, not become clinically significant.

\section{Sex applicability}

At times, clinical evidence linked to occupational exposures is derived from a majority of male subjects, which could be related to a male predominance in certain professions. ${ }^{110,111}$ Similarly, in most Western countries, cigarette smoking is still more prevalent in men than in women, although this gap has been closing steadily over the past decades. ${ }^{12,113}$ Nevertheless, the available in vivo and clinical evidence in support of the proposed AOP suggests that there is no remarkable gender difference.

\section{Application of the AOP}

Ultimately, the future application of this AOP lies in its potential for predicting decreased lung function in humans exposed to potentially harmful inhaled substances. This becomes especially pertinent as impaired lung function carries a significant risk of morbidity and mortality. Given the long latency period between exposure and detectable decreases in lung function, together with the fact that lung function tests alone may not be sufficiently sensitive to account for early lung damage that remains asymptomatic, ${ }^{114}$ means for early identification of potentially hazardous exposures are critical for the development of appropriate public health interventions. In this context, the proposed AOP could provide a starting point for developing simple cost-effective in vitro tests to screen compounds that may pose a risk to humans when inhaled and enable further classification based on the extent of harm they may cause. At the same time, biomarkers of effect/potential harm could be derived from the AOP, with the aim of developing reliable preclinical end points that are indicative of future disease or even mortality risk associated with impaired lung function. With this in mind, estimating the risk associated with regular e-cigarette use would be one example for the potential real-life applicability of this AOP. Long-term consequences of e-cigarette use with respect to lung health are currently unknown and are a topic of ongoing, and at times controversial, debate. ${ }^{115-118}$ The lack of chronic exposure data hampers a true assessment of how regular e-cigarette use might influence the mechanisms underlying mucus hypersecretion that ultimately lead to 
airway obstruction and, hence, a decline in lung function. Although e-cigarettes have now been in use for nearly a decade, those long-term data, including health outcomes of regular e-cigarette users, will not be available for a while. However, short-term observations, predominantly derived from in vitro assays, are beginning to accumulate. Multiple studies in lung epithelial cells exposed to e-cigarette aerosol showed, for example, increased ROS levels compared with air exposure (although those levels were still lower than those observed following cigarette smoke exposure). ${ }^{119-122}$ It would be of interest to confirm whether the subsequent event involves EGFR activation and downstream signaling, which is based on the AOP proposed in this study, an indicator that mucus hypersecretion and decreased lung function may be a long-term consequence of e-cigarette aerosol exposure. As such, this AOP could provide a framework for mapping out suitable in vitro models and tests allowing for the systematic evaluation of the KEs in the context of e-cigarette use. Moreover, such AOP-based in vitro tests may eventually also prove useful in substantiating the risk reduction potential of e-cigarettes as cessation aids or alternatives to cigarettes for smokers who cannot or do not want to quit.

\section{Acknowledgments}

The authors thank Ruth Dempsey and Christopher Proctor for their helpful discussions and critical review during the preparation of this article. The authors are also grateful to Edanz Editing for editorial assistance with this article.

\section{Author Disclosure Statement}

K.L., M.T., and J.H. are full-time employees of Philip Morris International (PMI). F.J.L., L.E.H., and M.G. are full-time employees of British American Tobacco (Investments) Ltd. J.P. was employed at Selventa at the time this project was undertaken, and Selventa received financial compensation from PMI for their services. The authors declare no further conflicts of interest with respect to the research, authorship, and/or publication of this article.

\section{References}

1. Rubin BK. Secretion properties, clearance, and therapy in airway disease. Transl Respir Med 2014:2;6.

2. Rose MC, Voynow JA. Respiratory tract mucin genes and mucin glycoproteins in health and disease. Physiol Rev 2006:86;245-278.

3. Nadel JA. Mucous hypersecretion and relationship to cough. Pulm Pharmacol Ther 2013:26;510-513.

4. Viegi $\mathrm{G}$, et al. Definition, epidemiology and natural history of COPD. Eur Respir J 2007:30;993-1013.

5. WHO. World Health Statistics. Geneva: World Health Organization; 2008.

6. Diaz-Guzman E, Mannino DM. Epidemiology and prevalence of chronic obstructive pulmonary disease. Clin Chest Med 2014:35;7-16.

7. Villeneuve DL, et al. Adverse outcome pathway (AOP) development I: Strategies and principles. Toxicol Sci 2014: $142 ; 312-320$.

8. OECD. Users' handbook supplement to the Guidance document for developing and assessing adverse outcome pathways. 2014.
9. Langley G, et al. Lessons from toxicology: Developing a 21st-century paradigm for medical research. Environ Health Perspect 2015:123;A268.

10. Yoshida T, Tuder RM. Pathobiology of cigarette smokeinduced chronic obstructive pulmonary disease. Physiol Rev 2007:87;1047-1082.

11. Kim V, Criner GJ. The chronic bronchitis phenotype in chronic obstructive pulmonary disease: Features and implications. Curr Opin Pulm Med 2015:21;133-141.

12. Burgel P, Nadel J. Roles of epidermal growth factor receptor activation in epithelial cell repair and mucin production in airway epithelium. Thorax 2004:59;992-996.

13. Heppner DE, van der Vliet A. Redox-dependent regulation of epidermal growth factor receptor signaling. Redox Biol 2016:8;24-27.

14. Higashiyama $S$, et al. Membrane-anchored growth factors, the epidermal growth factor family: Beyond receptor ligands. Cancer Sci 2008:99;214-220.

15. Burgel P-R, Nadel JA. Epidermal growth factor receptormediated innate immune responses and their roles in airway diseases. Eur Respir J 2008:32;1068-1081.

16. Polosa R, et al. Expression of c-erbB receptors and ligands in human bronchial mucosa. Am J Respir Cell Mol Biol 1999:20;914-923.

17. Aida S, et al. Distribution of epidermal growth factor and epidermal growth factor receptor in human lung: Immunohistochemical and immunoelectron-microscopic studies. Respiration 1994:61;161-166.

18. O'Donnell R, et al. Expression of ErbB receptors and mucins in the airways of long term current smokers. Thorax 2004:59;1032-1040.

19. Goldkorn T, et al. EGF-receptor phosphorylation and signaling are targeted by $\mathrm{H}_{2} \mathrm{O}_{2}$ redox stress. Am J Respir Cell Mol Biol 1998:19;786-798.

20. Van Winkle LS, Isaac JM, Plopper CG. Distribution of epidermal growth factor receptor and ligands during bronchiolar epithelial repair from naphthalene-induced Clara cell injury in the mouse. Am J Pathol 1997:151; 443-459.

21. de Boer WI, et al. Expression of epidermal growth factors and their receptors in the bronchial epithelium of subjects with chronic obstructive pulmonary disease. Am J Clin Pathol 2006:125;184-192.

22. Marinaş A, et al. Expression of epidermal growth factor (EGF) and its receptors (EGFR1 and EGFR2) in chronic bronchitis. Rom J Morphol Embryol 2011:53;957-966.

23. Kohr K, Ueki IF, Nadel JA. Neutrophil elastase induces mucin production by ligand-dependent epidermal growth factor receptor activation. Am J Physiol - Lung Cell Mol Physiol 2002:283;L531-40.

24. Shao MXG, Nadel JA. Neutrophil elastase induces MUC5AC mucin production in human airway epithelial cells via a cascade involving protein kinase $C$, reactive oxygen species, and TNF- $\alpha$-converting enzyme. J Immunol 2005:175;4009-4016.

25. Shim JJ, et al. IL-13 induces mucin production by stimulating epidermal growth factor receptors and by activating neutrophils. Am J Physiol Lung Cell Mol Physiol 2001:280; L134-L140.

26. Takeyama K, et al. Oxidative stress causes mucin synthesis via transactivation of epidermal growth factor receptor: Role of neutrophils. J Immunol 2000:164;1546-1552.

27. Casalino-Matsuda SM, et al. Role of hyaluronan and reactive oxygen species in tissue kallikrein-mediated epidermal 
growth factor receptor activation in human airways. J Biol Chem 2004:279;21606-21616.

28. Blanchet $\mathrm{S}$, et al. Fine particulate matter induces amphiregulin secretion by bronchial epithelial cells. Am J Respir Cell Mol Biol 2004:30;421-427.

29. Rumelhard M, et al. Expression and role of EGFR ligands induced in airway cells by PM2.5 and its components. Eur Respir J 2007:30;1064-1073.

30. Lemjabbar H, et al. Tobacco smoke-induced lung cell proliferation mediated by tumor necrosis factor alpha-converting enzyme and amphiregulin. J Biol Chem 2003:278;2620226207.

31. Deshmukh HS, et al. Matrix metalloproteinase-14 mediates a phenotypic shift in the airways to increase mucin production. Am J Respir Crit Care Med 2009:180;834845.

32. Kim JH, et al. Effects of matrix metalloproteinase inhibitor on LPS-induced goblet cell metaplasia. Am J Physiol Lung Cell Mol Physiol 2004:287;L127-L133.

33. Yoshisue H, Hasegawa K. Effect of MMP/ADAM inhibitors on goblet cell hyperplasia in cultured human bronchial epithelial cells. Biosci Biotechnol Biochem 2004:68; 2024-2031.

34. Val S, et al. Fine PM induce airway MUC5AC expression through the autocrine effect of amphiregulin. Arch Toxicol 2012:86;1851-1859.

35. Paulsen CE, et al. Peroxide-dependent sulfenylation of the EGFR catalytic site enhances kinase activity. Nat Chem Biol 2011:8;57-64.

36. DeYulia GJ, et al. Hydrogen peroxide generated extracellularly by receptor-ligand interaction facilitates cell signaling. Proc Natl Acad Sci U S A 2005:102;5044-5049.

37. $\mathrm{Wu} \mathrm{W}$, et al. Activation of the EGF receptor signaling pathway in human airway epithelial cells exposed to metals. Am J Physiol 1999:277;L924-L931.

38. Truong TH, et al. Molecular basis for redox activation of epidermal growth factor receptor kinase. Cell Chem Biol 2016:23;837-848.

39. Truong TH, Carroll KS. Redox regulation of EGFR signaling through cysteine oxidation. Biochemistry 2012:51; 9954-9965.

40. Ravid T, et al. Epidermal growth factor receptor activation under oxidative stress fails to promote $\mathrm{c}-\mathrm{Cbl}$ mediated down-regulation. J Biol Chem 2002:277;31214-31219.

41. Tyner JW, et al. Blocking airway mucous cell metaplasia by inhibiting EGFR antiapoptosis and IL-13 transdifferentiation signals. J Clin Invest 2006:116;309-321.

42. Curran DR, Cohn L. Advances in mucous cell metaplasia: A plug for mucus as a therapeutic focus in chronic airway disease. Am J Respir Cell Mol Biol 2010:42;268-275.

43. Kim S, Schein AJ, Nadel JA. E-cadherin promotes EGFRmediated cell differentiation and MUC5AC mucin expression in cultured human airway epithelial cells. Am J Physiol Lung Cell Mol Physiol 2005:289;L1049-L1060.

44. Hackel PO, et al. Epidermal growth factor receptors: Critical mediators of multiple receptor pathways. Curr Opin Cell Biol 1999:11;184-189.

45. Allahverdian S, et al. Sialyl Lewis X modification of the epidermal growth factor receptor regulates receptor function during airway epithelial wound repair. Clin Exp Allergy 2010:40;607-618.

46. Silva MA, Bercik P. Macrophages are related to goblet cell hyperplasia and induce MUC5B but not MUC5AC in human bronchus epithelial cells. Lab Invest 2012:92;937-948.
47. Rock JR, et al. Basal cells as stem cells of the mouse trachea and human airway epithelium. Proc Natl Acad Sci U S A 2009:106;12771-12775.

48. Lumsden AB, McLean A, Lamb D. Goblet and clara cells of human distal airways: Evidence for smoking induced changes in their numbers. Thorax 1984:39;844-849.

49. Reader JR, et al. Pathogenesis of mucous cell metaplasia in a murine asthma model. Am J Pathol 2003:162;2069-2078.

50. Turner J, et al. Goblet cells are derived from a FOXJ1expressing progenitor in a human airway epithelium. Am J Respir Cell Mol Biol 2011:44;276-284.

51. Evans CM, et al. Mucin is produced by Clara cells in the proximal airways of antigen-challenged mice. Am J Respir Cell Mol Biol 2004:31;382-394.

52. Lamb D, Reid L. Mitotic rates, goblet cell increase and histochemical changes in mucus in rat bronchial epithelium during exposure to sulphur dioxide. J Pathol Bacteriol 1968:96;97-111.

53. Shimizu T, et al. Hypertrophic and metaplastic changes of goblet cells in rat nasal epithelium induced by endotoxin. Am J Respir Crit Care Med 1996:153;1412-1418.

54. Harris JF, et al. Bcl-2 sustains increased mucous and epithelial cell numbers in metaplastic airway epithelium. Am J Respir Crit Care Med 2005:171;764-772.

55. Schwalm K, et al. Expression of the proapoptotic protein Bax is reduced in bronchial mucous cells of asthmatic subjects. Am J Physiol Lung Cell Mol Physiol 2008:294;L1102-L1109.

56. Casalino-Matsuda SM, Monzón ME, Forteza RM. Epidermal growth factor receptor activation by epidermal growth factor mediates oxidant-induced goblet cell metaplasia in human airway epithelium. Am J Respir Cell Mol Biol 2006:34;581-591.

57. Takeyama K, et al. Role of epidermal growth factor receptor in maintaining airway goblet cell hyperplasia in rats sensitized to allergen. Clin Exp Allergy 2008:38;857-865.

58. Oyanagi T, et al. Suppression of MUC5AC expression in human bronchial epithelial cells by interferon- $\gamma$. Allergol Int 2016:pii:S1323-8930(16)30060-0.

59. Di YP, Zhao J, Harper R. Cigarette smoke induces MUC5AC protein expression through the activation of Sp1. J Biol Chem 2012:287;27948-27958.

60. Hewson CA, Edbrooke MR, Johnston SL. PMA induces the MUC5AC respiratory mucin in human bronchial epithelial cells, via PKC, EGF/TGF- $\alpha$, Ras/Raf, MEK, ERK and Sp1dependent mechanisms. J Mol Biol 2004:344;683-695.

61. Lee YC, et al. 2,3,7,8-Tetrachlorodibenzo-p-dioxin-induced MUC5AC expression aryl hydrocarbon receptor-independent/EGFR/ERK/p38-dependent SP1-based transcription. Am J Respir Cell Mol Biol 2011:45;270-276.

62. Perrais M, et al. Induction of MUC2 and MUC5AC mucins by factors of the epidermal growth factor (EGF) family is mediated by EGF receptor/Ras/Raf/extracellular signalregulated kinase cascade and Sp1. J Biol Chem 2002:277; 32258-32267.

63. Young HWJ, et al. Central role of Muc5ac expression in mucous metaplasia and its regulation by conserved $5^{\prime}$ elements. Am J Respir Cell Mol Biol 2007:37;273-290.

64. Barbier D, et al. Influenza A induces the major secreted airway mucin MUC5AC in a protease-EGFR-extracellular regulated kinase-Sp1-dependent pathway. Am J Respir Cell Mol Biol 2012:47;149-157.

65. Hao Y, et al. Mycoplasma pneumoniae modulates STAT3STAT6/EGFR-FOXA2 signaling to induce overexpression of airway mucins. Infect Immun 2014:82;5246-5255. 
66. Zhen G, et al. IL-13 and epidermal growth factor receptor have critical but distinct roles in epithelial cell mucin production. Am J Respir Cell Mol Biol 2007:36;244-253.

67. Gensch E, et al. Tobacco smoke control of mucin production in lung cells requires oxygen radicals, AP-1 and JNK. J Biol Chem 2004:279;39085-39093.

68. Zhou J-S, et al. Autophagy plays an essential role in cigarette smoke-induced expression of MUC5AC in airway epithelium. Am J Physiol Lung Cell Mol Physiol 2016:310; L1042-L1052.

69. Ramos FL, Krahnke JS, Kim V. Clinical issues of mucus accumulation in COPD. Int $\mathbf{J}$ Chron Obstruct Pulmon Dis 2014:9;139-150.

70. Rogers DF. Physiology of airway mucus secretion and pathophysiology of hypersecretion. Respir Care 2007:52; 1134-1149.

71. Aoshiba K, Nagai A. Differences in airway remodeling between asthma and chronic obstructive pulmonary disease. Clin Rev Allergy Immunol 2004:27;35-43.

72. Vestbo J, Prescott E, Lange P. Association of chronic mucus hypersecretion with FEV1 decline and chronic obstructive pulmonary disease morbidity. Copenhagen City Heart Study Group. Am J Respir Crit Care Med 1996:153; $1530-1535$.

73. Song L, et al. The chronic and short-term effects of gefinitib on airway remodeling and inflammation in a mouse model of asthma. Cell Physiol Biochem 2016:38;194-206.

74. Ayers M, Jeffery P. Proliferation and differentiation in mammalian airway epithelium. Eur Respir J 1988:1;58-80.

75. Jefferey P, et al. Structural aspects of cigarette smokeinduced pulmonary disease. In: Smoking and the Lung. pp. 1-31. New York: Springer; 1984.

76. Hays SR, Fahy JV. Characterizing mucous cell remodeling in cystic fibrosis: Relationship to neutrophils. Am J Respir Crit Care Med 2006:174;1018-1024.

77. Tesfaigzi Y, et al. DNA synthesis and Bcl-2 expression during development of mucous cell metaplasia in airway epithelium of rats exposed to LPS. Am J Physiol Lung Cell Mol Physiol 2004:286;L268-L274.

78. Taniguchi K, et al. Epigen is induced during the interleukin13-stimulated cell proliferation in murine primary airway epithelial cells. Exp Lung Res 2011:37;461-470.

79. Takeyama K, Fahy J, Nadel J. Relationship of epidermal growth factor receptors to goblet cell production in human bronchi. Am J Respir Crit Care Med 2001:163;511-516.

80. Lee H-M, et al. Agarose plug instillation causes goblet cell metaplasia by activating EGF receptors in rat airways. Am J Physiol Lung Cell Mol Physiol 2000:278;L185-L192.

81. Hegab AE, et al. Niflumic acid and AG-1478 reduce cigarette smoke-induced mucin synthesis: The role of hCLCA1. Chest 2007:131;1149-1156.

82. Deshmukh HS, et al. Acrolein-activated matrix metalloproteinase 9 contributes to persistent mucin production. Am J Respir Cell Mol Biol 2008:38;446-454.

83. Deshmukh HS, et al. Metalloproteinases mediate mucin $5 \mathrm{AC}$ expression by epidermal growth factor receptor activation. Am J Respir Crit Care Med 2005:171;305-314.

84. Kim J-H, et al. Relation of epidermal growth factor receptor expression to mucus hypersecretion in diffuse panbronchiolitis. Chest 2004:126;888-895.

85. Burgel P-R, et al. Relation of epidermal growth factor receptor expression to goblet cell hyperplasia in nasal polyps. J Allergy Clin Immunol 2000:106;705-712.
86. Munkholm M, Mortensen J. Mucociliary clearance: Pathophysiological aspects. Clin Physiol Funct Imaging 2014:34; 171-177.

87. Caramori G, et al. MUC5AC expression is increased in bronchial submucosal glands of stable COPD patients. Histopathology 2009:55;321-331.

88. Innes AL, et al. Epithelial mucin stores are increased in the large airways of smokers with airflow obstruction. Chest 2006:130;1102-1108.

89. Allinson JP, et al. The presence of chronic mucus hypersecretion across adult life in relation to chronic obstructive pulmonary disease development. Am J Respir Crit Care Med 2015:193;662-672.

90. Pistelli R, Lange P, Miller DL. Determinants of prognosis of COPD in the elderly: Mucus hypersecretion, infections, cardiovascular comorbidity. Eur Respir J 2003:40;10s-14s.

91. Tesfaigzi Y. Roles of apoptosis in airway epithelia. Am J Respir Cell Mol Biol 2006:34;537-547.

92. Wu DY-C, et al. Distinctive epidermal growth factor receptor/extracellular regulated kinase-independent anddependent signaling pathways in the induction of airway mucin 5B and mucin 5AC expression by phorbol 12myristate 13-acetate. Am J Pathol 2007:170;20-32.

93. Kim Y-J, et al. Hypoxia-mediated mechanism of MUC5AC production in human nasal epithelia and its implication in rhinosinusitis. PLoS One 2014:9;e98136.

94. Wan $\mathrm{H}$, et al. Foxa2 regulates alveolarization and goblet cell hyperplasia. Development 2004:131;953-964.

95. OECD. Guidance document on developing and assessing adverse outcome pathways. Series on Testing and Assessment 2013. No. 184 (ENV/JM/MONO(2013)6).

96. Gökbulut AA, Kiraz Y, Baran Y. Cell proliferation and cytotoxicity assays. Curr Pharm Biotechnol 2016:17;12131221.

97. Riss TL, et al. Cell viability assays. In: Assay Guidance Manual [Internet]. GS Sittampalam, et al. Bethesda, MD: Eli Lilly \& Company and the National Center for Advancing Translational Sciences 2004-2013; 2016.

98. Archana M, et al. Various methods available for detection of apoptotic cells-A review. Indian J Cancer 2013:50; 274-283.

99. Muppidi J, Porter M, Siegel RM. Measurement of apoptosis and other forms of cell death. Curr Protoc Immunol 2004:Chapter 3:Unit 3.17.

100. Gomperts BN, et al. IL-13 regulates cilia loss and foxj1 expression in human airway epithelium. Am J Respir Cell Mol Biol 2007:37;339-346.

101. Rogers D. Airway goblet cells: Responsive and adaptable front-line defenders. Eur Respir J 1994:7;1690-1706.

102. Ekberg-Aronsson M, et al. Mortality in GOLD stages of COPD and its dependence on symptoms of chronic bronchitis. Respir Res 2005:6;98.

103. Vestbo J. Epidemiological studies in mucus hypersecretion. Novartis Found Symp 2002:248;3-12; discussion: 12-19, 277-282.

104. Miller MR, et al. Standardisation of spirometry. Eur Respir J 2005:26;319-338.

105. From the Global strategy for the diagnosis, management and prevention of COPD, Global Initiative for Chronic Obstructive Lung Disease (GOLD). http://goldcopd.org/2016 (last accessed December 30, 2016)

106. Vlahos R, Bozinovski S. Recent advances in pre-clinical mouse models of COPD. Clin Sci 2014:126;253-265. 
107. Nikula KJ, Green FH. Animal models of chronic bronchitis and their relevance to studies of particle-induced disease. Inhal Toxicol 2000:12(Suppl 4);123-153.

108. Rogers DF. Pulmonary mucus: Pediatric perspective. Pediatr Pulmonol 2003:36;178-188.

109. Parker JC, et al. Epidermal growth factor removal or tyrphostin AG1478 treatment reduces goblet cells \& mucus secretion of epithelial cells from asthmatic children using the air-liquid interface model. PLoS One 2015:10;e0129546.

110. Eng A, et al. Gender differences in occupational exposure patterns. Occupa Environ Med 2011:68:888-894.

111. Kennedy SM, et al. Environmental and occupational exposures: Do they affect chronic obstructive pulmonary disease differently in women and men? Proc Am Thorac Soc 2007:4;692-694.

112. Syamlal G, Mazurek JM, Dube SR. Gender differences in smoking among U.S. working adults. Am J Prev Med 2014:47;467-475.

113. Hitchman SC, Fong GT. Gender empowerment and female-to-male smoking prevalence ratios. Bull World Health Organ 2011:89;195-202.

114. Celli B, et al. Population impact of different definitions of airway obstruction. Eur Respir J 2003:22;268-273.

115. Meernik C, Goldstein AO. Should clinicians recommend e-cigarettes to their patients who smoke? No. Ann Fam Med 2016:14;302-303.

116. McNeill A. Should clinicians recommend e-cigarettes to their patients who smoke? Yes. Ann Fam Med 2016:14; 300-301.

117. Cahn Z, Siegel M. Electronic cigarettes as a harm reduction strategy for tobacco control: A step forward or a repeat of past mistakes? J Public Health Policy 2011:32;16-31.

118. Benowitz NL. Emerging nicotine delivery products. Implications for public health. Ann Am Thorac Soc 2014:11; 231-235.

119. Taylor M, et al. E-cigarette aerosols induce lower oxidative stress in vitro when compared to tobacco smoke. Toxicol Mech Methods 2016:26;465-476.

120. Scheffler $S$, et al. Evaluation of e-cigarette liquid vapor and mainstream cigarette smoke after direct exposure of primary human bronchial epithelial cells. Int J Environ Res Public Health 2015:12;3915-3925.

121. Scheffler S, et al. Cytotoxic evaluation of e-liquid aerosol using different lung-derived cell models. Int J Environ Res Public Health 2015:12;12466-12474.

122. Shivalingappa PC, et al. Airway exposure to e-cigarette vapors impairs autophagy and induces aggresome formation. Antioxid Redox Signal 2016:24;186-204.

123. Qi L, et al. Roles of ROS/TACE in neutrophil elastaseinduced mucus hypersecretion in NCI-H292 airway epithelial cells. Eur Cytokine Netw 2010:21;177-185.

124. Takeyama K, et al. Activation of epidermal growth factor receptors is responsible for mucin synthesis induced by cigarette smoke. Am J Physiol Lung Cell Mol Physiol 2001:280;L165-L172.

125. Burgel P-R, et al. Human eosinophils induce mucin production in airway epithelial cells via epidermal growth factor receptor activation. J Immunol 2001:167; 5948-5954.

126. Kim HJ, et al. The role of Nox 4 in oxidative stress-induced MUC5AC overexpression in human airway epithelial cells. Am J Respir Cell Mol Biol 2008:39;598-609.

127. Yu Q, et al. Caveolin-1 aggravates cigarette smoke extractinduced MUC5AC secretion in human airway epithelial cells. Int J Mol Med 2015:35;1435-1442.

128. $\mathrm{Yu} \mathrm{H}$, et al. Regulation of cigarette smoke-induced mucin expression by neuregulin $1 /$ /ErbB3 signalling in human airway epithelial cells. Basic Clin Pharmacol Toxicol 2011: $109 ; 63-72$.

129. Foster JE, et al. LPS-induced neutrophilic inflammation and Bcl-2 expression in metaplastic mucous cells. Am J Physiol Lung Cell Mol Physiol 2003:285;L405-L414.

130. Tesfaigzi J, Hotchkiss JA, Harkema JR. Expression of the Bcl-2 protein in nasal epithelia of F344/N rats during mucous cell metaplasia and remodeling. Am J Respir Cell Mol Biol 1998:18;794-799.

131. Tesfaigzi Y, et al. Bcl-2 in LPS- and allergen-induced hyperplastic mucous cells in airway epithelia of Brown Norway rats. Am J Physiol Lung Cell Mol Physiol 2000:279; L1210-L1217.

132. Hirota N, et al. Histamine may induce airway remodeling through release of epidermal growth factor receptor ligands from bronchial epithelial cells. FASEB J 2012:26; 1704-1716.

133. Shatos MA, et al. ERK/p44p42 mitogen-activated protein kinase mediates EGF-stimulated proliferation of conjunctival goblet cells in culture. Invest Ophthalmol Vis Sci 2008: 49;3351-3359.

134. Gu J, et al. Presence of EGF growth factor ligands and their effects on cultured rat conjunctival goblet cell proliferation. Exp Eye Res 2008:86;322-334.

135. Kim HJ, et al. Epicatechin gallate suppresses oxidative stress-induced MUC5AC overexpression by interaction with epidermal growth factor receptor. Am J Respir Cell Mol Biol 2010:43;349-357.

136. Aikawa $\mathrm{T}$, et al. Morphometric analysis of intraluminal mucus in airways in chronic obstructive pulmonary disease. Am Rev Respir Dis 1989:140;477-482.

137. Ma R, et al. MUC5AC expression up-regulation goblet cell hyperplasia in the airway of patients with chronic obstructive pulmonary disease. Chin Med Sci J 2005:20; 181-184.

Address correspondence to: Dr. Julia Hoeng

Philip Morris International Research and Development Philip Morris Products S.A. (Part of Philip Morris International Group of Companies)

Quai Jeanrenaud 5 2000 Neuchtel Switzerland

E-mail: julia.hoeng@pmi.com 